Article

\title{
Compact N-Band Tree-Shaped Multiplexer-Based Antenna Structures for 5G/IoT Mobile Devices
}

\author{
Amélia Ramos ${ }^{1,2, *}$, Tiago Varum ${ }^{1,2}$ iD and João N. Matos ${ }^{1,2} \mathbb{D}$ \\ 1 Instituto de Telecomunicações, Campus Universitário de Santiago, 3810-193 Aveiro, Portugal; \\ tiago.varum@ua.pt (T.V.); matos@ua.pt (J.N.M.) \\ 2 Universidade de Aveiro, Campus Universitário de Santiago, 3810-193 Aveiro, Portugal \\ * Correspondence: ameliaramos@ua.pt; Tel.: +351-234-377-900
}

Received: 9 October 2020; Accepted: 7 November 2020; Published: 8 November 2020

\begin{abstract}
This paper presents a simple, compact and low-cost design method that allows one to obtain low-profile multi-band antennas for the overcrowded future generation networks, which are widely versatile and very heterogeneous in the $\mathrm{K} / \mathrm{Ka}$ bands. The proposed antennas comprise $n$ radiating monopoles, one for each of the desired operating frequencies, along with a frequency selective feeding network fed at a single point. This concept enables a single antenna to be shared with different radio-frequency $(\mathrm{RF})$ frontends, potentially saving space. Typically, with $n$-band structures the biggest challenge is to make them highly efficient and here this is assured by multiplexing the frequency, and thus isolating each of the monopoles, allowing the design of scalable structures which fit the 5G applications. Based on the vision proposed here, a dual-band and a tri-band structures were built and characterized by their main parameters. Both prototypes achieved peak efficiencies around $80 \%$, with adequate bandwidths and gains, as well as great compactness.
\end{abstract}

Keywords: frequency multiplexed; IoT; millimeter-waves; multi-band; n-band antenna; antenna as a sensor

\section{Introduction}

It is clear that the global tendency of exchanged data traffic is growing exponentially and, with it, the number of interconnected devices, pushing existing systems to their limits. In addition to the increasing traffic on each network, the variety of the services supported is increasing too, which naturally gives rise to great concerns about energy consumption. In this sense, $5 \mathrm{G}$ wireless systems must fulfil three main requirements: (i) have high throughput; (ii) serve many users simultaneously; and (iii) have less energy consumption [1], the latter being probably the biggest driving force of 5G. Associated with this, the high user mobility will force new antenna designs and new concepts to be implemented [2].

In addition, migration to mmWaves becomes mandatory, because despite implying higher propagation issues, it is probably the most effective way to achieve the necessary bandwidth [3]. In these frequencies, new challenges arise, given the reduced dimensions, however, there is an inherent opportunity to produce compact solutions and an increasing demand for robust multipurpose dual-band or multi-band antenna systems for 5G applications. Today, mobile devices comprise a wide range of applications and features, most of them involving several communication frontends, and also multiple antennas, requiring space, which can create problems such as the coupling between them.

A possible solution to combat the lack of available space resulting from this growing incorporation of communication systems, is to develop a single antenna, operating in each frequency band, and shared by the various communication systems. Figure 1 clarifies the scenario referring to a mobile device where a single antenna structure interacts with multiple radio-frequency frontends, which can be one 
of the main characteristic nowadays, since even a common smartphone gathers multiple antennas, enabling the connection with the most varied services.

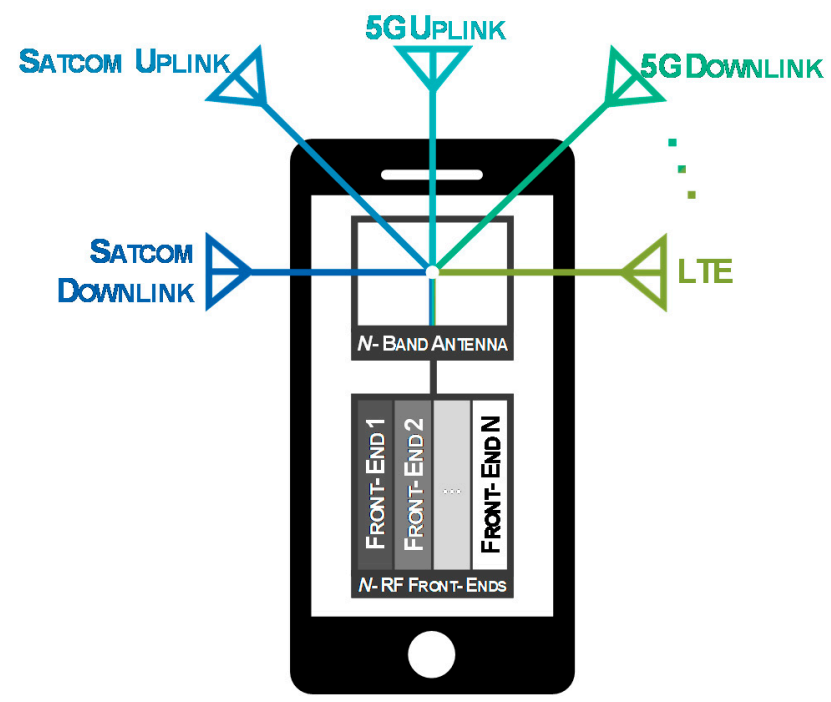

Figure 1. Single N-Band Antenna Shared by Multiple Frontends.

There are several ways to design an antenna that meets these requirements. One is through the bandwidth, i.e. producing an ultra-wideband antenna, however, it this (obtaining a band that includes all the necessary frequencies) is an almost impossible condition, especially given the disparity of frequency bands used. In addition, isolation between bands and frontends would not be guaranteed, decreasing the efficiency.

Another possibility is to develop antennas resonating in different bands, which are the commonly named multi-band antennas. This option consists of a process with a high degree of randomness, since in most cases this is done at the expense of deformations of the radiating structure, presenting little freedom to the control of the antenna's properties. There is also the group of reconfigurable antennas (in this case, in terms of frequency), although these antennas are much more complex because they are active and require additional control to select the operating frequency. In addition, these antennas use switches in the form of discrete elements, which consume energy. Due to all this, an alternative design is proposed.

This paper is divided into 6 sections, starting with this introduction. Section 2 presents a careful revision of the related works, focusing on multi-band antennas and in frequency-selective feeding structures. Then, in Section 3 the design principle is presented, clarifying the concept proposed. Section 4 contains all methods and presents the structures developed, each in a different sub-section. The results, both measured and simulated can be found in Section 5, as well as the prototypes built. Finally, major conclusions can be found in Section 6.

\section{Related Work}

In this way, several authors have tested the feasibility of reducing the number of antennas in each equipment and thereby saving space. In [2] a structure based on a dual-band slot is proposed and is designed to operate at $28 / 38 \mathrm{GHz}$. Along with the operating frequencies, this antenna exhibits adequate bandwidth values, as well as adequate gains for incorporation in a $5 \mathrm{G}$ mobile device. Despite the interesting results, this work lacks measures and the authors end up defending their proposal by comparing CST with HFSS.

In [4] another dual-band antenna in a massive MIMO arrangement is described. This structure is based on a series-fed antenna array and one can denote high gains (of more than $12 \mathrm{~dB}$ at each band) and good radiation patterns, however, once again, only simulation values are shown. 
On the contrary, in [5] the measurement results support the work on a substrate integrated waveguide (SIW) antenna array for the Ka-band. There, authors implemented a linear array to improve the overall antenna's performance and they were able to achieve satisfactory bandwidths (lower than $5 \%$ ) and proper gain measurements (around $5 \mathrm{dBi}$ ). The authors claim that by using the presented structure, multi-band antennas can be designed, but no implementation is shown to prove this statement.

Additionally, a dual-band dual-circularly-polarized antenna operating in the Ka-band is presented in [6]. The work is supported by simulated and measured results, however, a mediocre correspondence can be denoted between simulations and measurements. The gain, both in the uplink and downlink bands, is improved when the radiating element is implemented into an array, however measurements regarding axial ratio are poor, the complexity is huge and both the antenna's scalability and the robustness are questionable.

When it comes to tri-band antennas, neither the microstrip patch antenna presented in [7] nor the antenna array with defected ground seen in ref. [8] show any measures confirming their respective simulations. Both structures have resonances in the mmWaves region, along with suitable bandwidths and gains. In [7] the efficiency values shown are quite high, whereas in [8] these values are not mentioned.

Additionally, a scalable structure can be found in [9]. It proposes a compact dual-band and small slot antenna without compromising its performance. Measurements show good correspondence with simulations, as well as good gain, considering the typical values for slot antennas. Apart from these good results, one could argue that the major contribution of the work is its scalability, since authors defend that by adding more slots to the structure the desired multi-band behavior can be achieved. Nevertheless, the structure proposed operates at 2.4/5.2 GHz, very low frequencies for the $5 \mathrm{G}$ context.

Recently, an aperture-sharing integration methodology implementing a $3.5 / 28 \mathrm{GHz}$ antenna with mmWave beam steering capability was proposed [10]. The main concept is to share the aperture of a linear $28 \mathrm{GHz}$ array, comprised by four separately fed dipoles, with a $3.5 \mathrm{GHz}$ dipole antenna. Favorable results were obtained regarding a stable mmWave beam at different scanning angles, meanwhile with broad impedance bandwidths in both operating bands (over 20\%). Nevertheless, only one of the resonating frequencies suits the mmWave spectrum region and the overall size of the structure is close to the size of a single $3.5 \mathrm{GHz}$ dipole antenna, which, in many of the future applications may be inappropriate.

In [11] an interesting approach is conducted on using the half-mode substrate integrated waveguide (HMSIW) technique to design low-profile cavity-backed multi-band antennas. Authors designed single, dual and triple band structures to validate the multi band responses which indicated favorable results on the radiation patterns' stability and the front-to-back ratio. Moreover, the radiation efficiency being higher than $80 \%$ at the operating frequencies is a quite encouraging result to test this concept of introducing U-shaped strips outside the aperture of an HMSIW cavity in the mmWaves region of the electromagnetic spectrum, since the tests made were at the C-band.

In [12], an architecture whose main objective is to solve the bandwidth limitations of phased arrays was proposed. The suggested design includes five printed quasi-Yagi antennas, which should be placed in the upper edge of a mobile device. Their placement, and the orientation of the active element and the directors are crucial to solve such bandwidth limitations. With the suggested configuration and by not using phase shifters and simply switching the feeding to one of the quasi-Yagi elements it is possible to scan the desired areas. However, this switchable antenna system results in a physically larger setup, since only one antenna is used at a time, which when compared to the phased array is a disadvantage, as in these structures, antenna area can be saved, as the whole aperture is exploited.

Another structure which explores alternative designs is presented in [13]. Considering the advantages of omnidirectional radiation patterns in communicating regardless of direction, a modified fork-shaped microstrip monopole antenna with a probe feed line shows wideband and multi-band characteristics. Here, the impedance bandwidth is improved by designing a dual-triangle portion of the ground plane, yet the resonant frequencies are quite low, suitable for example for the GSM band. 
Regarding the emerging MIMO systems, in [14] a MIMO antenna system for multi-band 5G (mmWave) and wideband 4G application is shown. This structure works at triple bands (28, 37 and $39 \mathrm{GHz})$ for $5 \mathrm{G}$ and the wideband $(1.8-2.6 \mathrm{GHz})$ for $4 \mathrm{G}$. Each one of the MIMO elements consists of a slot in the ground plane and two microstrip feeding ports in the top layer (the isolation is also enhanced by using a low pass filter). Indeed, this design can work as a tapered slot antenna for 5G, covering 27.5-40 GHz or as an open-ended slot antenna for 4G covering 1.8-2.6 GHz. However, as noted, in the $5 \mathrm{G}$ band one denotes wideband operation, instead of multiple resonances at the frequencies of interest.

One of the major challenges of a multi-band antenna structures is its efficiency, a specification that gains further importance when operating in the mmWave region. The major contribution of this work is the microstrip feeding arrangement, which allows to section the antenna into $n$ frequency-selective parts. In the literature, other techniques can be found to improve the feeding network's efficiency.

In [15], an antenna array consisting of five radiating elements is designed and measured, operating at the $2-4 \mathrm{GHz}$ range, achieving a beamwidth around 24 degrees. The frequency selective feeding network delivers the signal to the selected elements at $2 f_{0}$ and gradually switches the signal between elements as the frequency decreases to $f_{0}$. The major advantage of this strategy is an almost constant beamwidth over a broad frequency range.

A similar concept is presented in [16] where a six-element antenna array operating in $1.75-3.5 \mathrm{GHz}$ frequency range is seen. In this report, the feeding network uses a directional filter where the adjustment of coupled-line sections allows for the flexible selection of transmission coefficients. This structure permits a constant beamwidth in an octave frequency range the signal is redirected from the center elements to the outer elements. In the end, this feeding network's achievements are reached at the expense of a single directional filter and equal split power dividers.

More recently in [17] an interesting approach on multi-band filtering slot antennas is proposed. There, authors realize a duplexing and filtering antenna by integrating a multi-band antenna and the multimode resonator. The work is validated since three antennas were designed, fabricated and measured. Although the correspondence between simulations and measurements is quite satisfactory, neither the antenna's scalability is a priority nor the operating frequency is suitable for the future generation of mobile communications. Above all, the concept proposed in [17] requires the usage of two feeding ports, which differs from the goal of this work which lies on having a single antenna, fed in a single point, capable of interacting with multiple RF frontends, isolating each frequency.

All of these suggested frequency selective networks are associated with higher complexity in the structure's design and fabrication. They demand for additional components and the antennas were designed for lower frequencies than what is expected within the 5G context. The work presented here defends an innovative concept where neither the manufacturing is compromised nor the feeding network imposes the usage of any additional components.

In this sense a new concept to design a structure for a multi-band antenna operating in the $\mathrm{K} / \mathrm{Ka}$ bands is proposed. The design idea lies on sectioning a n-band antenna into $n$ parts, having each section properly isolated (in frequency) in order to maximize the efficiency, and that is achieved by applying the adequate impedance matching as it will be explained later. This frequency multiplexing concept represents the main difference between the state-of-the-art studied and the structures proposed in this report. With this alternative it is possible to several antennas in a single structure with a single feeding point. Two prototypes were built and tested representing the cases of a dual and a tri-band antenna, ensuring the scalability to other resonances.

\section{Design Principle}

Devices which operate in multiple bands are highly interesting, given the wide and varied protocols that they are equipped to operate. To exemplify, the architecture of a current smartphone includes capabilities to operate with different communication technologies such as Wi-Fi, Bluetooth, GSM, 3G/4G (LTE), GPS, NFC, among others. In addition to multiple radios, these devices require several antennas, increasing interferences and couplings, and it is an ever more difficult task to 
accommodate them due to the reduced space available. It is in this context that a new concept for designing a multi-band antenna, is inserted.

Figure 2 presents a schematic example of a multi-band antenna for modern terminals. As noted, the antenna structure in the example operates in the downlink and uplink bands of 5G, SATCOM and LTE. In the illustration, instead of five antennas, with this concept it is possible to design a single antenna operating in all desired bands, with only one feeding point.

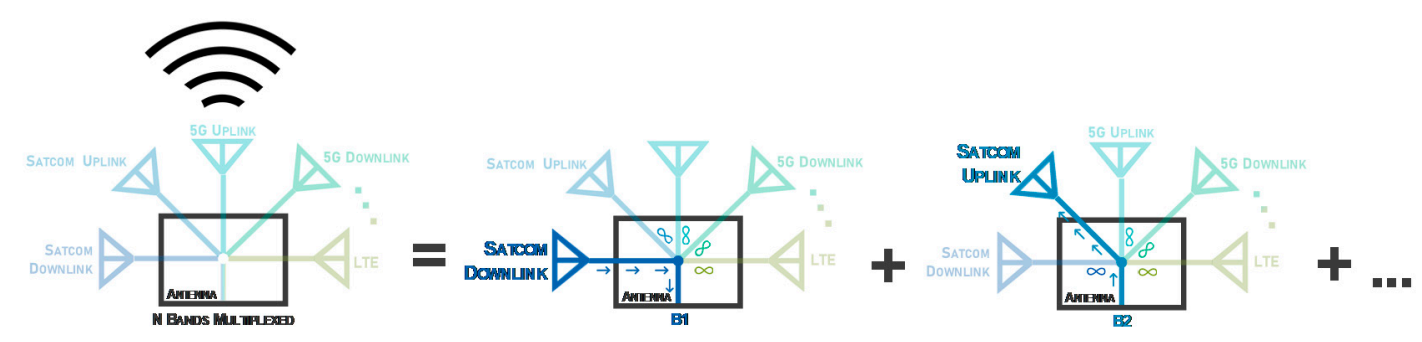

Figure 2. Schematic of the Main Design Concept.

Being an antenna shared by different radios, it is important to assure isolation between all bands, that is, that each RF frontend receives/transmits information using only its respective resonating element. The project begins with the design of all $n$ resonant antenna elements, one for each operating frequency. After having the $n$ radiating elements, the feeding structure ensures the high global efficiency of the antenna, forcing theoretically infinite impedances in the operating bands of neighboring elements, clearly conducting the signal towards/from the respective resonant element.

As an example, Figure 2 can be analyzed in depth, where in the middle schematic the user wants to receive data in the SATCOM downlink band, and thus the path is clear for the respective frequency band B1, and for all the other operating bands the impedance seen will be infinite. This concept is scalable for the $n$ different bands of the antenna. In short, this concept allows to design a $n$-band structure as efficient as the summation of several resonant antennas in each of the $n$ bands.

\section{Methods and Structures}

The great advantage of having the prototype composed of $n$ sections is to guarantee that for each operation frequency, the input impedance is only imposed by the respective resonant element. This leads to a very efficient feeding network, in line with the challenging requirements of 5G, massive IoT and the future satellite communications.

Nowadays, wireless communications systems are mainly equipped using printed antennas $[18,19]$ mostly due to their low cost and ease of fabrication. Another important aspect is the ability to produce various structures, with unlimited design shapes and typologies. Bearing in mind the need to ensure communication regardless of direction, monopole and dipole-based structures present interesting advantages.

In order to verify the practicability of this concept, it was decided to demonstrate it, designing two prototypes, a dual band and a tri-band antenna. Starting with the dual-band model, it is composed by two printed monopoles, each resonant at a different frequency, $28 \mathrm{GHz}$ and $38 \mathrm{GHz}$ respectively. Additionally, confirming the scalability of the concept, a tri-band antenna was developed, and for this, a radiator at $20 \mathrm{GHz}$ was added. Both schemes are presented in Figure 3, clarifying the arrangement and the impedances expected in different parts of the structure.

The key aspect of these antennas is the feeding structure. The sectioning of this antenna into different parts lies on the existence of the connection points presented in Figure 3, thus, to scale this concept to a $n$-band antenna, $n-1$ connection points are required. These connection points represent the division of the feeding network. In the example, for a dual-band antenna, there is one single connection point, however, for the tri-band structure, two connection points are required, and so on. 


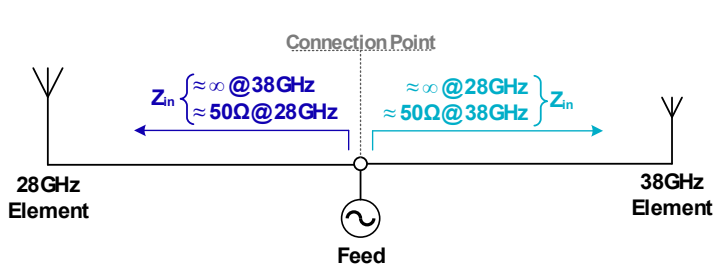

(a)

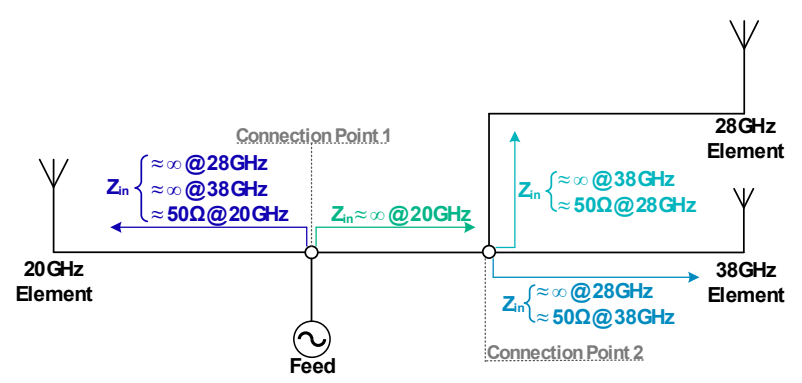

(b)

Figure 3. Schemes Proposed for the (a) Dual-Band and (b) Tri-Band antenna.

The resulting parts of the overall antenna have an adequate matching at the resonant frequency of the respective radiating element, while simultaneously showing a close to infinite impedance at the frequency of the opposite radiating element. Therefore, at each resonant frequency, a parallel association of infinite impedances with a characteristic impedance of interest is observable.

Clarifying with Figure $3 \mathrm{a}$, at the connection point and looking at the $28 \mathrm{GHz}$ element: at the resonant frequency, $28 \mathrm{GHz}$, an adequate matching is verified ensuring that it works properly, and, at the same time, the feeding network warrants that at $38 \mathrm{GHz}$ a very high impedance appears. These principles are applied symmetrically to the opposite side of the structure.

Both antennas proposed are designed over a single layer of the dielectric substrate Rogers RO4350B, which main properties include a dielectric constant $\varepsilon_{\mathrm{r}}=3.48$, thickness $h=0.254 \mathrm{~mm}$ and dissipation factor of $\tan (\delta)=0.0037 @ 10 \mathrm{GHz}$. All simulations have been carried out using the electromagnetic simulator software which is the Computer Simulation Technology Microwave Studio Suite (CST-MWS).

\subsection{Dual-Band Antenna Design}

Figure 4 identifies the main design parameters of the dual-band structure. Two monopoles with dimensions $L M p 28 \times W M p 28$ and $L M p 38 \times W M p 38$ were designed. A $50 \Omega$ impedance microstrip line, along with a quarter-wavelength transformer lead the input signal to the connection point referred above. Additionally, in order to maximize the structure's compactness, meander lines were used for the greater stubs.

From the connection point up to the monopoles, there is a group of microstrip lines which guarantees the adequate matching (at the desired frequency) and the close to infinite impedance at the adjacent operating band.

The acceptable matching is achieved by the colored identified lines highlighted in Figure 4a. These lines' dimensions and placement were implemented bearing the main concepts of microwave propagation. Starting with the open-ended stub named Stub 1, which has a $90^{\circ}$ electrical length of $90^{\circ}$ at $38 \mathrm{GHz}$, it turns infinite impedance into a short circuit. Naturally, Line 2, having the same electrical length at $38 \mathrm{GHz}$, converts the above-mentioned short circuit once again into a very high impedance at $38 \mathrm{GHz}$.

Through this pair of lines, the first requirement at the connection point is guaranteed: an (close to) infinite impedance at $38 \mathrm{GHz}$. However, these lines surely also influence the impedance in this part of the antenna, at $28 \mathrm{GHz}$. Therefore, the third line, Stub 3, was placed to compensate for this undesired influence, ensuring the impedance matching at $28 \mathrm{GHz}$.

Symmetrically, on the other side of the connection point, there is an open-ended stub, immediately followed by another stub, both with an electrical length of $90^{\circ}$ at $28 \mathrm{GHz}$, enabling the open circuit in the connection point at $28 \mathrm{GHz}$. Subsequently, a third stub once again compensates the influence in the antenna matching observed at $38 \mathrm{GHz}$. 


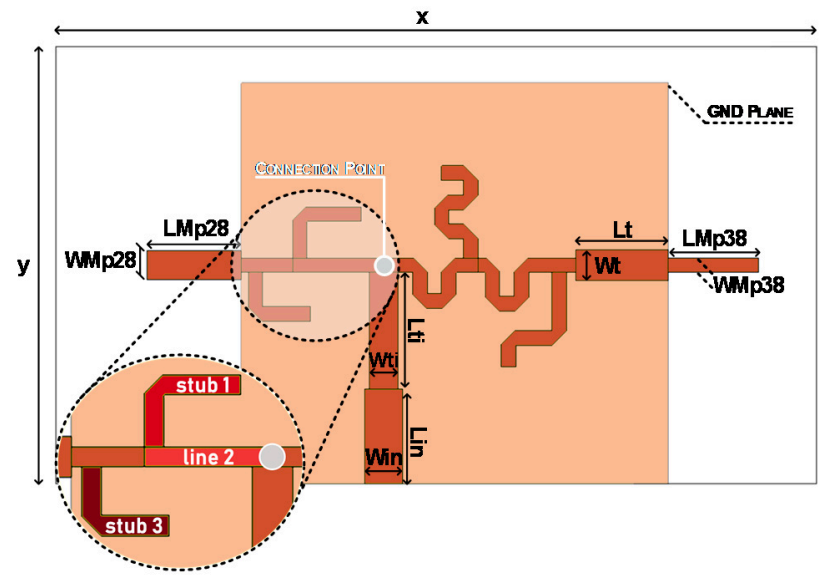

(a)

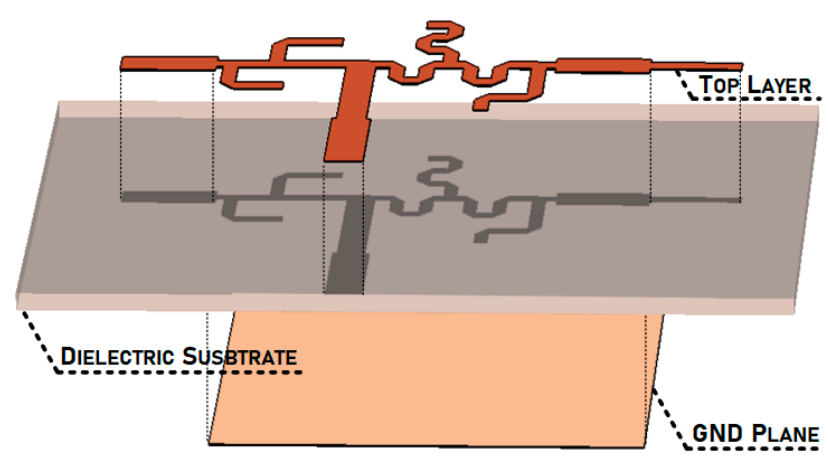

(b)

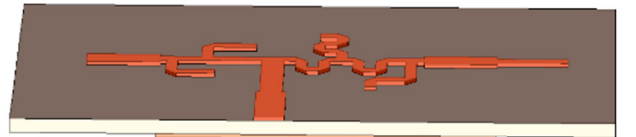

(c)

Figure 4. Dual-Band Antenna: (a) Design Parameters, (b) Layers Identification and (c) Final Structure.

After bearing all theoretical propagation considerations, the dual-band antenna optimized design parameters are presented in Table 1 and the feeding network line width is constant throughout the antenna $(0.2 \mathrm{~mm})$, with the exception of the quarter-wavelength transformer $(L t i \times W t i)$ and the $50 \Omega$ input line $(\operatorname{Lin} \times \mathrm{Win})$, connected to the single feeding point.

Table 1. Dual-Band Antenna's Dimensions.

\begin{tabular}{cc}
\hline Parameter & Dimension \\
\hline LMp28 & 1.30 \\
WMp28 & 0.40 \\
LMp38 & 1.24 \\
WMp38 & 0.20 \\
Lt & 1.28 \\
Wt & 0.4115 \\
Lti & 1.60 \\
Wti & 0.40 \\
Lin & 1.30 \\
Win & 0.5228 \\
x & 10.50 \\
$y$ & 6.00 \\
\hline
\end{tabular}

\subsection{Tri-Band Antenna Design}

Using the same method as before, and considering both the impedance requirements showed in Figure 3 and the design principle of Section 3, the tri-band antenna was designed over the same 
dielectric substrate used for the dual-band structure and its main design parameters are presented in Figure 5.

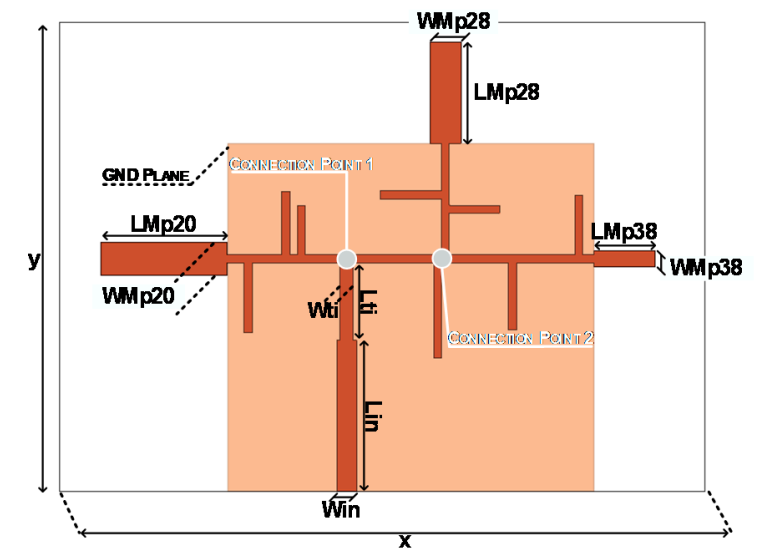

(a)

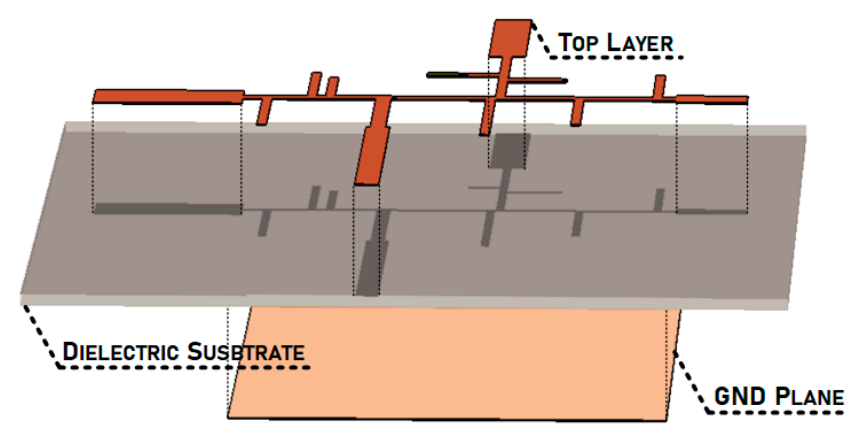

(b)

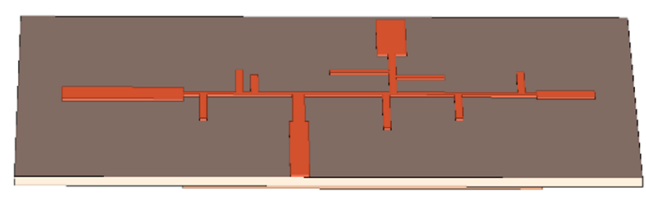

(c)

Figure 5. Tri-Band Antenna: (a) Design Parameters, (b) Layers Identification and (c) Final Structure.

The three resonant elements are easily denoted in Figure 5 through their associated design parameters LMpx $\times W M p x$. The main design parameters are listed in Table 2. All microstrip lines designed have $0.2 \mathrm{~mm}$ width, apart from the $50 \Omega$ input line $(\operatorname{Lin} \times$ Win $)$ and the quarter-wavelength transformer $(L t i \times W t i)$, as in the dual-band example. In this case, the final version of the monopoles has lengths equivalent to $0.4 \lambda_{d}, 0.45 \lambda_{d}$ and $0.37 \lambda_{d}$, regarding the 20 , the 28 and the $38 \mathrm{GHz}$ monopoles, respectively.

Table 2. Tri-Band Antenna's Dimensions.

\begin{tabular}{cc}
\hline Parameter & Dimension \\
\hline LMp20 & 3.25 \\
WMp20 & 0.86 \\
LMp28 & 2.60 \\
WMp28 & 0.80 \\
LMp38 & 1.557 \\
WMp38 & 0.43 \\
Lti & 2.00 \\
Wti & 0.33 \\
Lin & 3.90 \\
Win & 0.51 \\
x & 16.50 \\
y & 12.00 \\
\hline
\end{tabular}




\section{Results and Measurements}

The previously described prototypes were simulated and built and they are shown in Figure 6. It is important to mention that regarding the tri-band structure, Figure $6 \mathrm{~b}$ presents a connectorized version of the antenna, where the length of the $50 \Omega$ input feed line is excessive and just needed to place the connector. The antennas were measured, and the main results obtained are presented throughout this section.

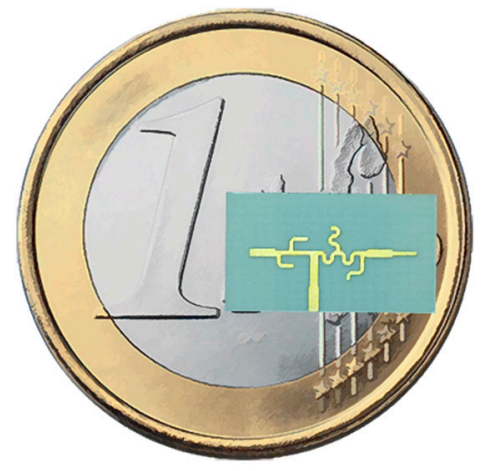

(a)

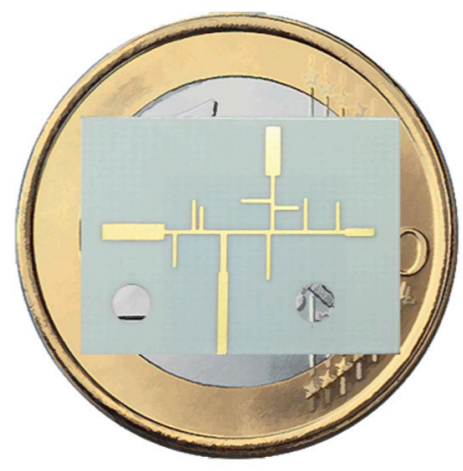

(b)

Figure 6. Prototypes Built: (a) Dual-Band and (b) Tri-Band Antennas.

Figure 7 exhibits the simulated and measured results of the reflection coefficient for the dual-band structure.

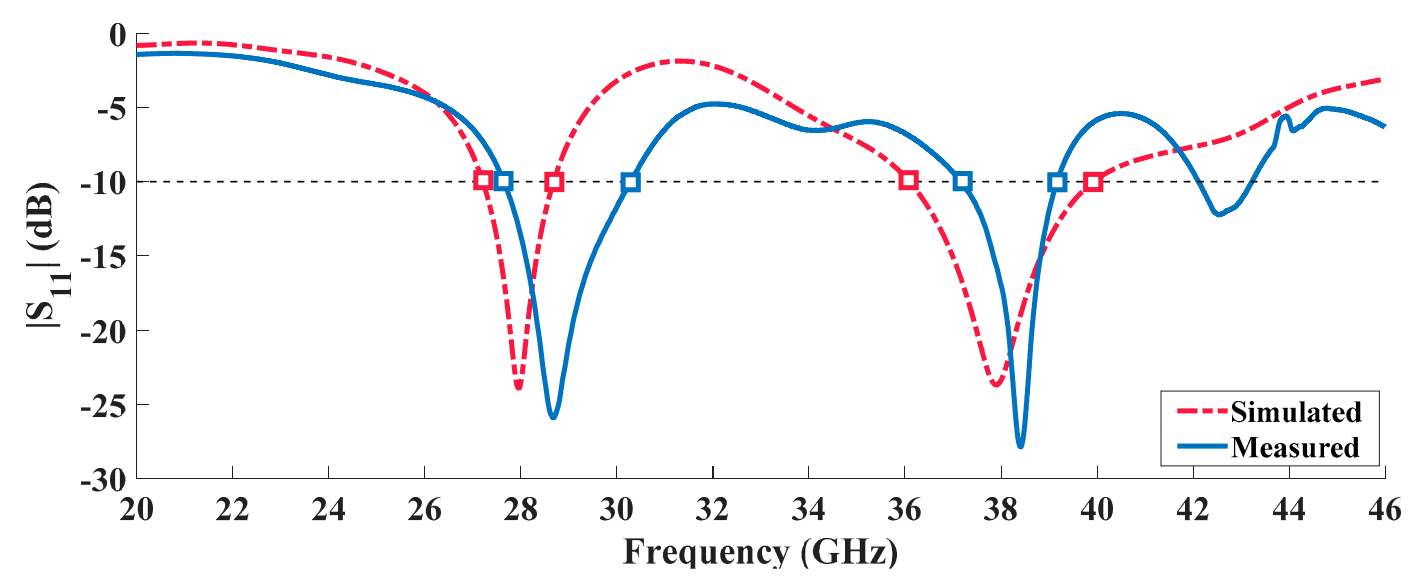

Figure 7. Simulated and Measured Reflection Coefficient of the Dual-Band Antenna.

For this prototype, a good impedance matching was achieved, with both curves presenting a similar behavior despite some frequency shifts of $680 \mathrm{MHz}$ and $410 \mathrm{MHz}$ from the desired 28 and $38 \mathrm{GHz}$, respectively. These small discrepancies seen might be justified either by slight construction imperfections (which is something natural given the antennas' small size). Nevertheless, the measured values of $S_{11}$ at the operation frequencies are $-13.64 \mathrm{~dB}$ and $-16.94 \mathrm{~dB}$, respectively, making of these results quite satisfactory.

Regarding the bandwidth, and considering the $S_{11}<10 \mathrm{~dB}$ criteria, the prototype achieved an operating band of $2.55 \mathrm{GHz}$ [27.54-30.09 GHz], representing 8.8\% bandwidth around $28 \mathrm{GHz}$. On the other hand, around $38 \mathrm{GHz}$, a $1.98 \mathrm{GHz}$ [37.2-39.18 GHz] band was reached, meaning 5.2\%. Table 3 summarizes the measured and simulated results of the dual-band radiating element. 
Table 3. Dual-Band $S_{11}$ Parameter Characteristics.

\begin{tabular}{cccc}
\hline & Measured Frequency Shift & Simulated Bandwidth & Measured Bandwidth \\
\hline & & $1.48 \mathrm{GHz}$ & $2.55 \mathrm{GHz}$ \\
Around $28 \mathrm{GHz}$ & $680 \mathrm{MHz}$ & {$[27.22-28.7 \mathrm{GHz}]$} & {$[27.54-30.09 \mathrm{GHz}]$} \\
& & $5.3 \%$ & $8.8 \%$ \\
Around $38 \mathrm{GHz}$ & $410 \mathrm{MHz}$ & $3.84 \mathrm{GHz}$ & $1.98 \mathrm{GHz}$ \\
& & {$[36.08-39.92 \mathrm{GHz}]$} & {$[37.2-39.18 \mathrm{GHz}]$} \\
& & $10.1 \%$ & $5.2 \%$ \\
\hline
\end{tabular}

The second prototype built proves the concept here proposed in a tri-band antenna. Figure 8 identifies a reasonable impedance matching between simulated and measured results in respect to the reflection coefficient, since the minimum value for $S_{11}$ occurs at the frequencies of interest, despite the slight frequency shifts around $20 \mathrm{GHz}$ and $38 \mathrm{GHz}$.

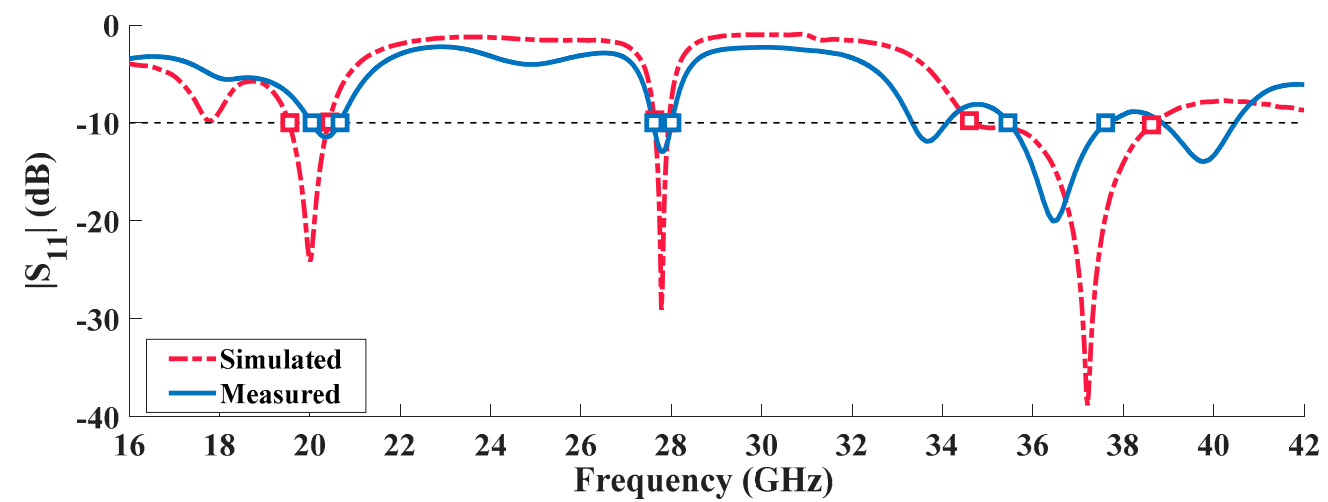

Figure 8. Simulated and Measured Reflection Coefficient of the Tri-Band Antenna.

These minor mismatches can be once again justified by the same reasons presented for the previous prototype: construction imperfections, or dielectric permittivity variations. Regarding the first operation band (at $20 \mathrm{GHz}$ ), the antenna shows a measured bandwidth of $0.62 \mathrm{GHz}$, equivalent to $3 \%$. At the other operation frequencies, $0.4 \mathrm{GHz}$ and $2.16 \mathrm{GHz}$ are seen at 28 and $38 \mathrm{GHz}$ respectively. Table 4 summarizes the measured and simulated results of the tri-band radiating structure.

Table 4. Tri-Band $S_{11}$ Parameter Characteristics.

\begin{tabular}{lccc}
\hline & Measured Frequency Shift & Simulated Bandwidth & Measured Bandwidth \\
\hline \multirow{2}{*}{ Around $20 \mathrm{GHz}$} & \multirow{2}{*}{$330 \mathrm{MHz}$} & $0.88 \mathrm{GHz}$ & $0.62 \mathrm{GHz}$ \\
& & {$[19.56-20.44 \mathrm{GHz}]$} & {$[20.05-20.67 \mathrm{GHz}]$} \\
Around $28 \mathrm{GHz}$ & $190 \mathrm{MHz}$ & $4.4 \%$ & $3 \%$ \\
& & $0.29 \mathrm{GHz}$ & $0.4 \mathrm{GHz}$ \\
Around $38 \mathrm{GHz}$ & \multirow{2}{*}{$1.5 \mathrm{GHz}$} & {$[27.64-27.93 \mathrm{GHz}]$} & {$[27.61-28.01 \mathrm{GHz}]$} \\
& & $1.1 \%$ & $1.4 \%$ \\
& & $4.03 \mathrm{GHz}$ & $2.16 \mathrm{GHz}$ \\
& & {$[34.60-38.62 \mathrm{GHz}]$} & {$[35.45-37.61 \mathrm{GHz}]$} \\
\hline
\end{tabular}

Through the reflection coefficient of the latest prototype analyzed it is possible to confirm the adequacy of the prototypes built and more importantly the principle of design proposed seems to guarantee the impedance matching.

Other aspect that sustains the appropriate performance of these antennas in 5G and the massive IoT scenario is the information about the antennas' efficiency, which is presented in Figures 9 and 10, regarding the dual and the tri-band radiating structures, respectively. 


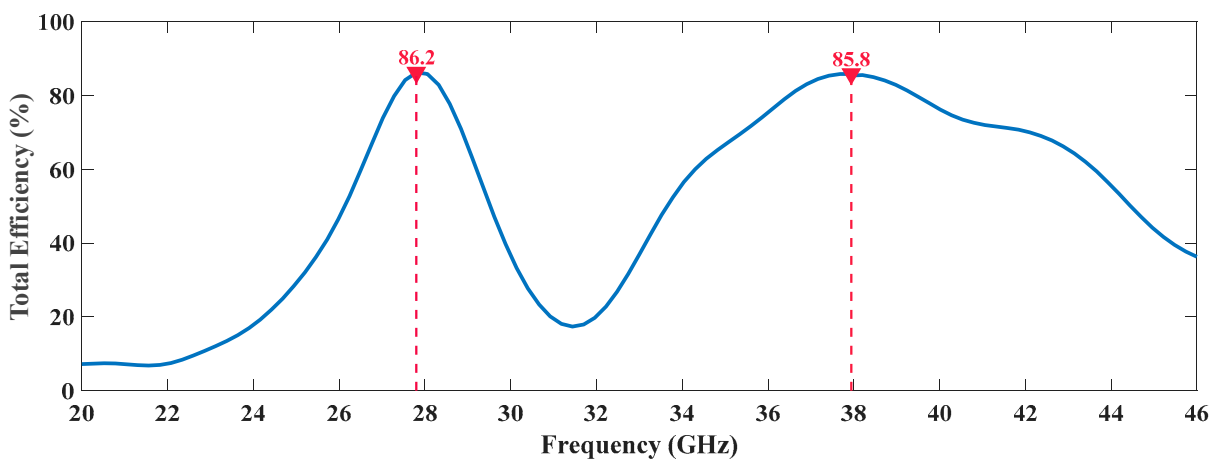

Figure 9. Efficiency Variation Over Frequency of the Dual-Band Antenna.

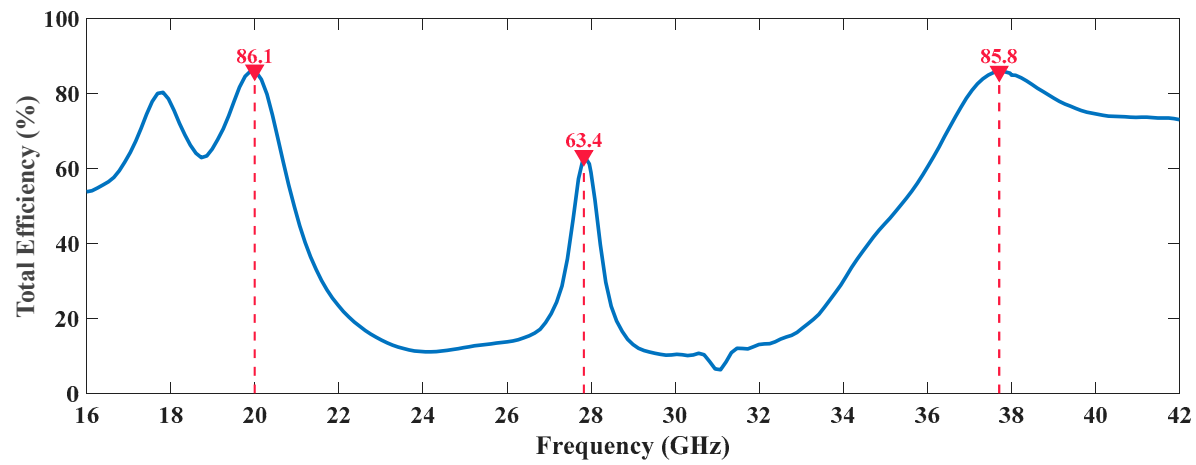

Figure 10. Efficiency Variation Over Frequency of the Tri-Band Antenna.

Figure 9 presents the simulated efficiency of the dual-band antenna over the frequency. Naturally two local maximums are highlighted. These maximums are according to expected since they appear adjacent to the frequencies of operation. Their magnitude is higher than $85 \%$ in both operating frequencies, an important value given the structure's compactness and size.

Similarly, for the tri-band antenna, there are clearly three local maximums in Figure 10, which are once again, near the frequencies of interest, in this case 20,28 and $38 \mathrm{GHz}$, confirming the proper functioning of the antenna.

Besides the efficiency peaks, the surface current distribution also confirms the proper functioning of the feeding network, verifying once again the frequency multiplexed structure achieved. Figure 11 starts by presenting the surface current distribution at the operating frequencies of the dual-band antenna, $28 \mathrm{GHz}$ and $38 \mathrm{GHz}$.

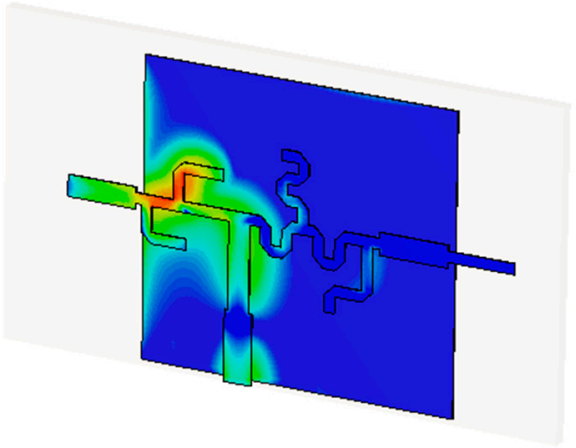

(a)

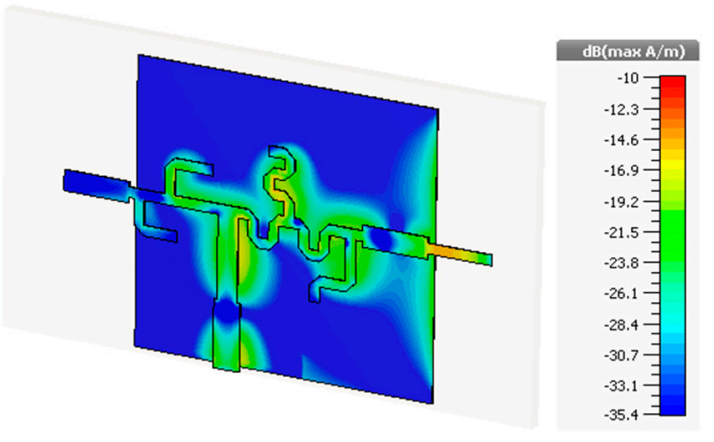

(b)

Figure 11. Surface Current Distribution at (a) $28 \mathrm{GHz}$ and (b) $38 \mathrm{GHz}$.

It can be easily observed that, for both frequencies, only the respective resonant monopole is being fed. The opposite monopole has no current flowing at all. 
Figure 12 exhibits the respective results for the tri-band structure, denoting the surface current distribution for the three operating frequencies.

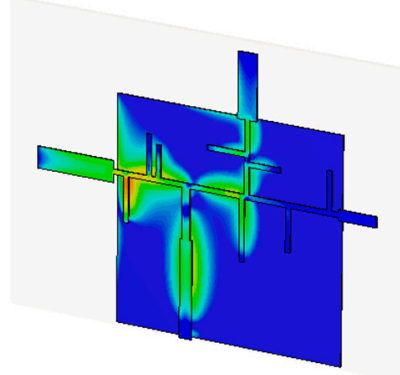

(a)

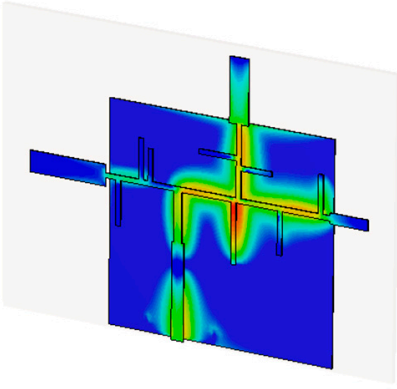

(b)

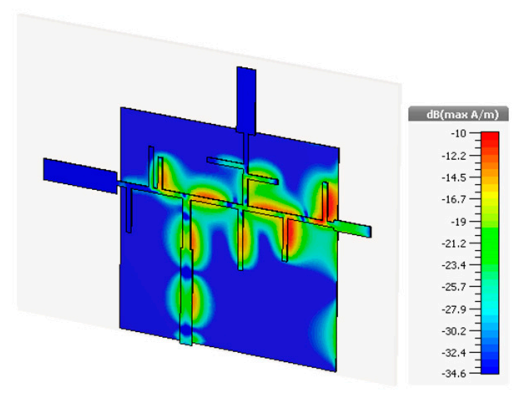

(c)

Figure 12. Surface Current Distribution at (a) $20 \mathrm{GHz}$, (b) $28 \mathrm{GHz}$ and (c) $38 \mathrm{GHz}$.

Once again at each one of the resonant frequencies, only the respective monopole has any current through it, all the others remain not fed. With this, it is possible to state that the frequency multiplexing concept proposed allowed to isolate, in frequency, each radiating element, maintaining a single input feed and without requiring any additional filters.

Figures 13 and 14 show the gain variation of both prototypes over frequency, highlighting the respective values at the operating frequencies. It is possible to verify that, in the tri-band case, the gain values vary between $2.5 \mathrm{dBi}$ and $4.5 \mathrm{dBi}$, in the frequencies of interest and they are mainly dependent on the antenna structure.

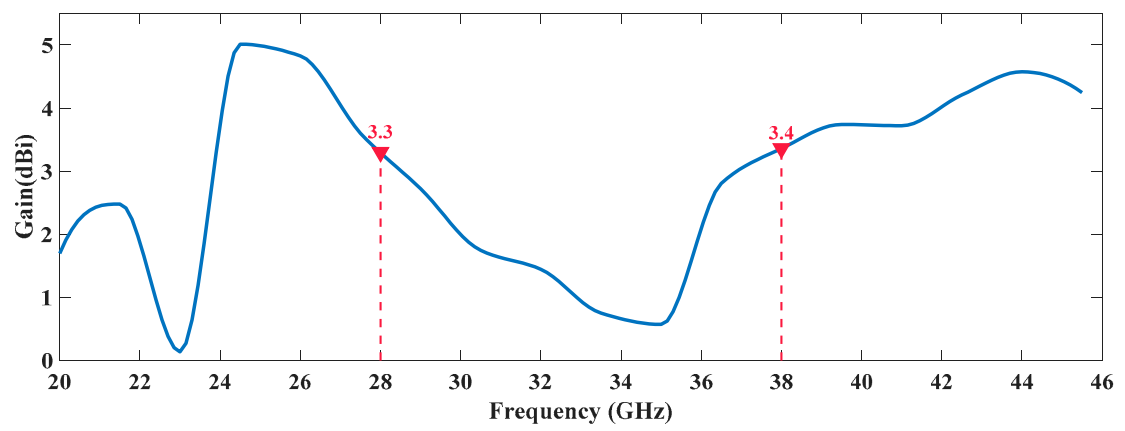

Figure 13. Gain Variation Over Frequency of the Dual-Band Antenna.

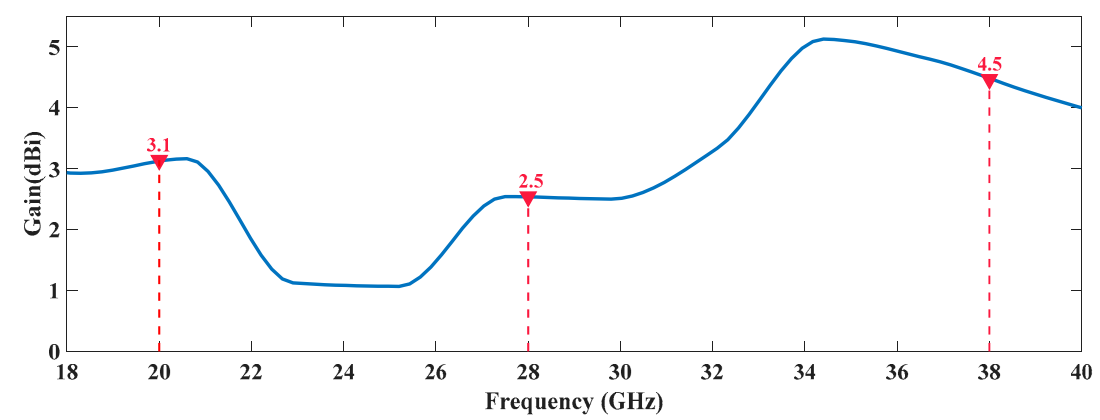

Figure 14. Gain Variation Over Frequency of the Tri-Band Antenna.

Regarding the gain of the antennas, in Figure 15 it is possible to observe the simulation and measured results of the two main radiation planes at both frequencies of interest, $28 / 38 \mathrm{GHz}$, for the dual band antenna. 


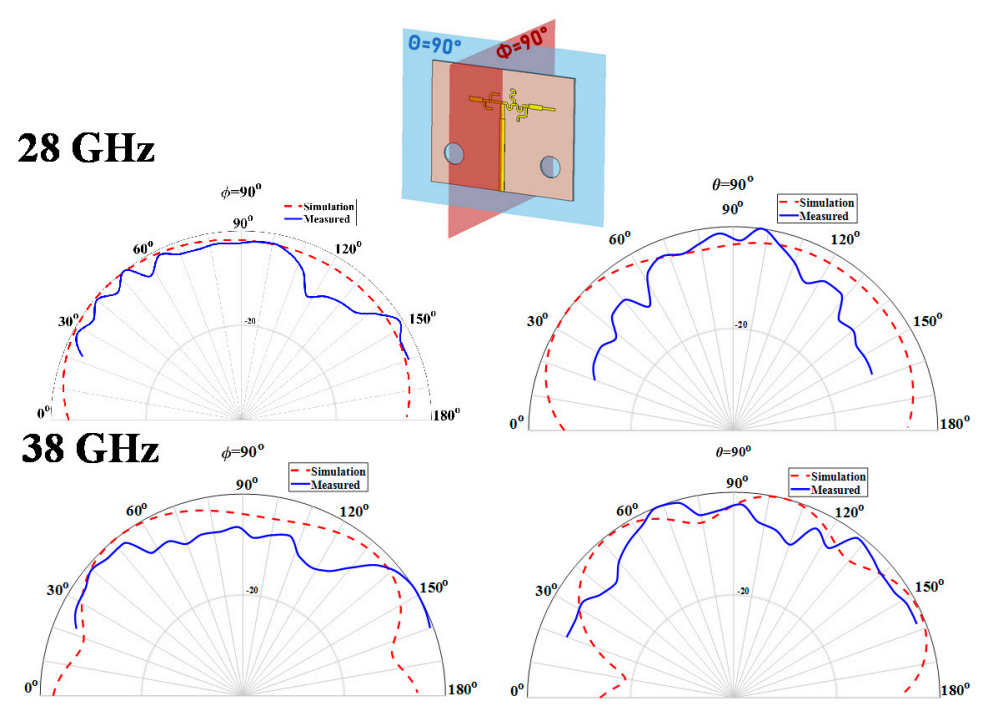

Figure 15. Simulated and Measured Normalized Radiation Pattern of the Dual-Band Antenna at $28 \mathrm{GHz}$ and $38 \mathrm{GHz}$.

As it is natural in very compact structures, particularly in multi-band antennas, the radiation patterns obtained seem a bit distorted from what was expected to be seen in monopoles. Apart from that, the dual-band antenna presents a maximum simulated gain of $3.3 \mathrm{dBi}$ at $28 \mathrm{GHz}$, while at $38 \mathrm{GHz}$ that value is $3.4 \mathrm{dBi}$.

When it comes to the tri-band antenna, the same two radiation planes are shown, but now for the three frequencies of interest. These results are presented in Figure 16 and a similar distortion in the radiation pattern shapes is observed. This radiating structure achieved a maximum simulated gain of $3.1,2.5$ and $4.5 \mathrm{dBi}$ at 20,28 and $38 \mathrm{GHz}$.
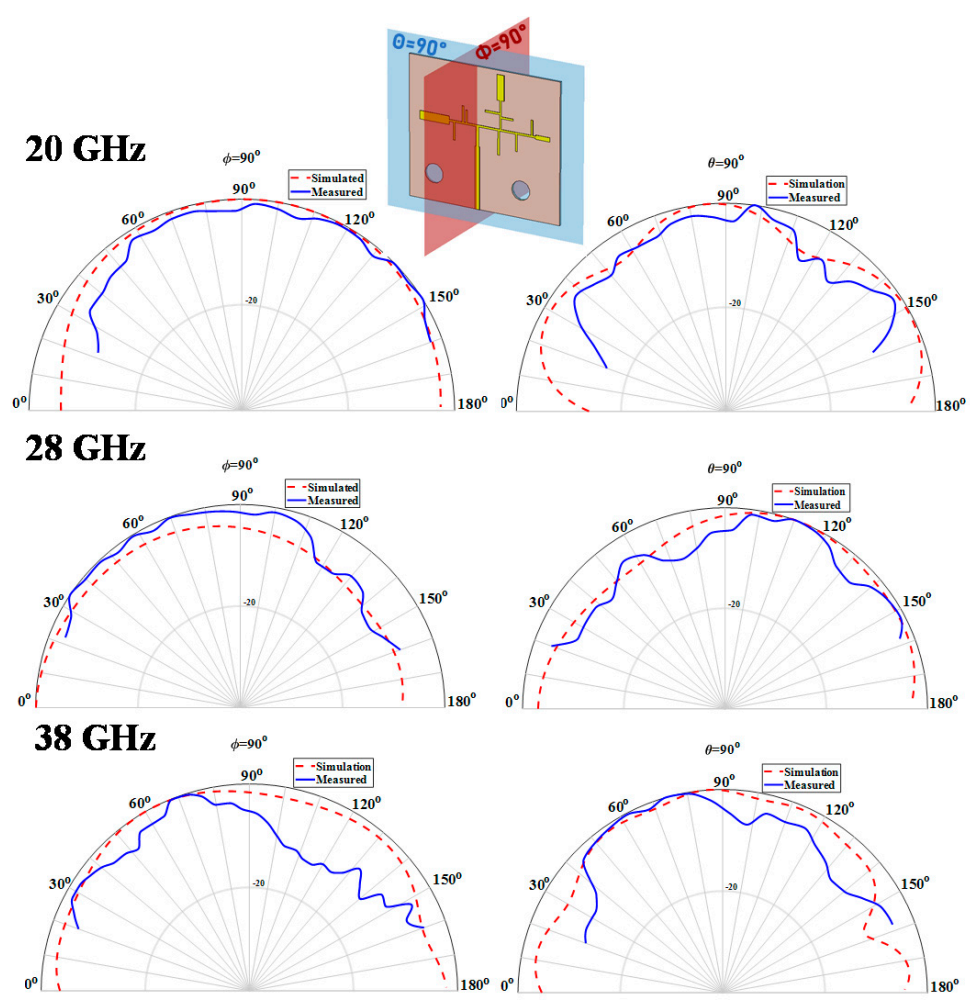

Figure 16. Simulated and Measured Normalized Radiation Pattern of the Tri-Band Antenna at 20/28/38 GHz. 
The main achievements of these structures are summarized and compared with the current state-of-the-art of dual and tri-band antennas in Table 5, analyzing the publication year (PY), the operating frequencies, bandwidth, size, scalability and the isolation in frequency factor.

Table 5. State-of-the-Art of Multi-Band Antennas: Main Results.

\begin{tabular}{|c|c|c|c|c|c|c|}
\hline $\begin{array}{l}\text { [Ref.] } \\
\text { PY }\end{array}$ & Antenna's Description & $\begin{array}{l}\text { Operating } \\
\text { Frequencies }\end{array}$ & Bandwidth & Measurements & Scalability & $\begin{array}{l}\text { Frequency } \\
\text { Isolation }\end{array}$ \\
\hline $\begin{array}{c}{[2]} \\
2015\end{array}$ & Dual-Band Slot-Based & $28 / 38 \mathrm{GHz}$ & $\begin{array}{l}24-30 \mathrm{GHz} \\
34-41 \mathrm{GHz}\end{array}$ & No & No & No \\
\hline $\begin{array}{c}{[4]} \\
2016\end{array}$ & Series-Fed Antenna Array & $28 / 38 \mathrm{GHz}$ & $\begin{array}{c}27.8-28.6 \mathrm{GHz} \\
36-38.6 \mathrm{GHz}\end{array}$ & No & No & No \\
\hline $\begin{array}{c}{[5]} \\
2015 \\
\end{array}$ & SIW Antenna Array & $28 / 38 \mathrm{GHz}$ & $\begin{array}{l}0.32 \mathrm{GHz} \\
1.9 \mathrm{GHz}\end{array}$ & No & No & No \\
\hline $\begin{array}{c}{[6]} \\
2017\end{array}$ & Annular Ring Slots & $20 / 30 \mathrm{GHz}$ & $\begin{array}{c}20.13-20.8 \mathrm{GHz} \\
30-30.85 \mathrm{GHz}\end{array}$ & Yes & Yes & No \\
\hline $\begin{array}{c}{[7]} \\
2018\end{array}$ & Microstrip Patch & $24.4 / 28 / 38 \mathrm{GHz}$ & $\begin{array}{l}\text { 23.6-24.4 GHz } \\
27.2-28.4 \mathrm{GHz} \\
37.3-38.1 \mathrm{GHz} \\
\end{array}$ & No & No & No \\
\hline $\begin{array}{c}{[8]} \\
2019\end{array}$ & $\begin{array}{l}\text { Antenna Array with } \\
\text { Defected Ground }\end{array}$ & $29 / 37.4 / 41 \mathrm{GHz}$ & $\begin{array}{c}28.5-29.7 \mathrm{GHz} \\
36.7-38 \mathrm{GHz} \\
40-42.1 \mathrm{GHz}\end{array}$ & No & No & No \\
\hline $\begin{array}{c}{[9]} \\
2008\end{array}$ & $\begin{array}{l}\text { Printed Slot-Based } \\
\text { Structures }\end{array}$ & 2.4/5.2 GHz & $\begin{array}{l}2.48-3.02 \mathrm{GHz} \\
3.81-5.65 \mathrm{GHz}\end{array}$ & Yes & Yes & No \\
\hline $\begin{array}{l}{[10]} \\
2020\end{array}$ & $\begin{array}{c}\text { Aperture-Sharing } \\
\text { Technique with a } 4 \text { Unit } \\
\text { Linear Array and a Dipole }\end{array}$ & $3.5 / 28 \mathrm{GHz}$ & $\begin{array}{l}3.12-3.84 \mathrm{GHz} \\
24.9-30.6 \mathrm{GHz}\end{array}$ & Yes & No & No \\
\hline \multirow{2}{*}{$\begin{array}{l}{[11]} \\
2019\end{array}$} & \multirow{2}{*}{$\begin{array}{l}\text { Cavity-Backed Antennas } \\
\text { using HMSIW Technique }\end{array}$} & $4.6 / 5.48 \mathrm{GHz}$ & $\begin{array}{l}91 \mathrm{MHz} \\
20 \mathrm{MHz}\end{array}$ & Yes & Yes & No \\
\hline & & $4.5 / 5 / 5.5 \mathrm{GHz}$ & $\begin{array}{l}70 \mathrm{MHz} \\
20 \mathrm{MHz} \\
20 \mathrm{MHz}\end{array}$ & Yes & Yes & No \\
\hline $\begin{array}{l}{[13]} \\
2004\end{array}$ & $\begin{array}{l}\text { Fork-Shaped Microstrip } \\
\text { Monopole Antenna }\end{array}$ & $860 / 2280 \mathrm{MHz}$ & $\begin{array}{c}731-987 \mathrm{MHz} \\
1498-3080 \mathrm{MHz}\end{array}$ & No & No & No \\
\hline \multirow{2}{*}{$\begin{array}{l}\text { This } \\
\text { Work }\end{array}$} & \multirow{2}{*}{$\begin{array}{l}\text { Monopole-Based with } \\
\text { Frequency Selective } \\
\text { Feeding Network }\end{array}$} & $28 / 38 \mathrm{GHz}$ & $\begin{array}{l}27.54-30.09 \mathrm{GHz} \\
37.2-39.18 \mathrm{GHz}\end{array}$ & Yes & Yes & Yes \\
\hline & & $20 / 28 / 38 \mathrm{GHz}$ & $\begin{array}{l}20.05-20.67 \mathrm{GHz} \\
27.61-28.01 \mathrm{GHz} \\
35.45-37.61 \mathrm{GHz}\end{array}$ & Yes & Yes & Yes \\
\hline
\end{tabular}

Knowing that one of the main concerns of this letter is the microstrip frequency-selective feeding network able to maximize the efficiency as well as easing he interaction of a single antenna with multiple RF Frontends, Table 6 compiles some of the state-of-the-art works related to the frequency multiplexing argued, showing how it was obtained and the main characteristics of the antenna structure.

Table 6. State-of-the-Art in Frequency Selective Antenna Structures: Main Results.

\begin{tabular}{|c|c|c|c|c|c|c|}
\hline $\begin{array}{l}\text { [Ref.] } \\
\text { PY }\end{array}$ & $\begin{array}{l}\text { Antenna's } \\
\text { Description }\end{array}$ & $\begin{array}{c}\text { Central } \\
\text { Frequencies }\end{array}$ & $\begin{array}{c}\text { Frequency Isolation } \\
\text { Technique }\end{array}$ & $\begin{array}{l}\text { Feeding } \\
\text { Network } \\
\text { Complexity }\end{array}$ & $\begin{array}{c}\text { Number of } \\
\text { Ports/Element }\end{array}$ & $\begin{array}{c}\text { Does it Require } \\
\text { Additional } \\
\text { Components? }\end{array}$ \\
\hline $\begin{array}{l}{[14]} \\
2019\end{array}$ & $\begin{array}{l}\text { Ground Tapered Slot } \\
\text { and Microstrip } \\
\text { Feeders }\end{array}$ & $2 / 32.5 \mathrm{GHz}$ & Low-Pass Filter & High & 2 & Yes \\
\hline $\begin{array}{l}{[15]} \\
2016\end{array}$ & Antenna Array & $3 \mathrm{GHz}$ & $\begin{array}{l}3 \mathrm{~dB} \text { directional } \\
\text { couplers + Schiffman } \\
\mathrm{C} \text { sections + Filters } \\
\text { and Power Dividers }\end{array}$ & Extreme & 1 & Yes \\
\hline
\end{tabular}


Table 6. Cont.

\begin{tabular}{|c|c|c|c|c|c|c|}
\hline $\begin{array}{l}\text { [Ref.] } \\
\text { PY }\end{array}$ & $\begin{array}{l}\text { Antenna's } \\
\text { Description }\end{array}$ & $\begin{array}{c}\text { Central } \\
\text { Frequencies }\end{array}$ & $\begin{array}{c}\text { Frequency Isolation } \\
\text { Technique }\end{array}$ & $\begin{array}{l}\text { Feeding } \\
\text { Network } \\
\text { Complexity }\end{array}$ & $\begin{array}{l}\text { Number of } \\
\text { Ports/Element }\end{array}$ & $\begin{array}{c}\text { Does it Require } \\
\text { Additional } \\
\text { Components? }\end{array}$ \\
\hline $\begin{array}{l}{[16]} \\
2017\end{array}$ & Antenna Array & $2.6 \mathrm{GHz}$ & $\begin{array}{l}\text { Directional Filter and } \\
\text { Power Dividers }\end{array}$ & High & 1 & Yes \\
\hline \multirow{2}{*}{$\begin{array}{l}{[17]} \\
2020\end{array}$} & \multirow{2}{*}{$\begin{array}{l}\text { Filtering Slot } \\
\text { Antennas }\end{array}$} & $3.5 / 5.2 \mathrm{GHz}$ & \multirow[b]{2}{*}{$n$-mode resonators } & \multirow[b]{2}{*}{ Medium } & \multirow[b]{2}{*}{2} & \multirow[b]{2}{*}{ No } \\
\hline & & $2.5 / 3.5 / 5.1 \mathrm{GHz}$ & & & & \\
\hline \multirow{2}{*}{$\begin{array}{l}\text { This } \\
\text { Work }\end{array}$} & \multirow{2}{*}{$\begin{array}{l}\text { Monopole-Based with } \\
\text { Frequency Selective } \\
\text { Feeding Network }\end{array}$} & $28 / 38 \mathrm{GHz}$ & \multirow{2}{*}{ Impedance Matching } & \multirow{2}{*}{ Low } & \multirow{2}{*}{1} & \multirow{2}{*}{ No } \\
\hline & & $20 / 28 / 38 \mathrm{GHz}$ & & & & \\
\hline
\end{tabular}

\section{Conclusions}

In this paper, a new multi-band antenna design concept is proposed, explained and proved through some practical prototypes. The main basis is the use of a feeding structure which ensure the impedance matching at a given operating frequency, isolating the structure at the remaining frequencies. When compared with an eventual alternative of a radiator with dual resonance, the option here presented, besides maximizing the efficiency, it avoids the usage of any bulky filters at the input.

This strategy was implemented in a dual-band and a tri-band prototypes, both suitable to integrate in IoT sensors. Individually these antennas present good impedance bandwidths for all frequencies of interest, since the smallest measured value is $400 \mathrm{MHz}$.

Regarding the antennas' gain, and considering that these structures are based in monopoles, these values are also satisfactory, especially when allied to the efficiency values witnessed. More importantly, the proposed concept of producing a $n$-band antenna has proven not only to work, but it also assures higher efficiency values than what is commonly seen in the state-of-the-art for multi-band antennas.

Author Contributions: All the authors have contributed to this paper. A.R. has designed the proposed antennas, performed the simulations and the measurements, and wrote the paper. T.V. and J.N.M. have supervised the entire research, the approach used, the results analysis, and discussion. Additionally, both have strongly contributed to the writing of the paper. All authors have read and agreed to the published version of the manuscript.

Funding: This work was partially supported by FCT/MCTES through national funds and when applicable cofunded EU funds under the project UIDB/50008/2020-UIDP/50008/2020 and the European Regional Development Fund through the Competitiveness and Internationalization Operational Program, Regional Operational Program of Lisbon, Regional Operational Program of the Algarve, in component FEDER, and the Foundation for Science and Technology, Project RETIOT, POCI-01-0145-FEDER-016432.

Conflicts of Interest: Authors declare no conflict of interest.

\section{References}

1. Ngo, H. Massive MIMO: Fundamentals and System Designs; Linköping University Electronic Press: Linköping, Sweden, 2015.

2. Haraz, O.; Ali, M.; Alshebeili, S.; Sebak, A. Design of a 28/38 GHz dual-band printed slot antenna for the future 5G mobile communication Networks. In Proceedings of the 2015 IEEE International Symposium on Antennas and Propagation \& USNC/URSI National Radio Science Meeting, Vancouver, BC, Canada, 19-25 July 2015. [CrossRef]

3. Samsung. 5G Vision. February 2015. Available online: https://www.samsung.com/global/business/networks/ insights/whitepaper/?white-paper (accessed on 9 October 2018).

4. Ali, M.; Sebak, A. Design of compact millimeter wave massive MIMO dual-band (28/38 GHz) antenna array for future 5G communication systems. In Proceedings of the 2016 17th International Symposium on Antenna Technology and Applied Electromagnetics (ANTEM), Montreal, QC, Canada, 10-13 July 2016. [CrossRef]

5. Ashraf, N.; Haraz, O.; Ashraf, M.; Alshebeili, S. 28/38-GHz dual-band millimeter wave SIW array antenna with EBG structures for 5G applications. In Proceedings of the 2015 International Conference on Information and Communication Technology Research (ICTRC), Abu Dhabi, UAE, 17-19 May 2015. [CrossRef] 
6. Mener, S.; Gillard, R.; Roy, L. A Dual-Band Dual-Circular-Polarization Antenna for Ka-Band Satellite Communications. IEEE Antennas Wirel. Propag. Lett. 2017, 16, 274-277. [CrossRef]

7. Kamal, M.; Islam, M.; Uddin, M.; Imran, A. Design of a Tri-Band Microstrip Patch Antenna for 5G Application. In Proceedings of the 2018 International Conference on Computer, Communication, Chemical, Material and Electronic Engineering (IC4ME2), Rajshahi, Bangladesh, 8-9 February 2018. [CrossRef]

8. Naqvi, S.N.; Azam, M.; Amin, Y.; Arshad, F.; Loo, J.; Tenhunen, H. Tri-Band Antenna Array with Defected Ground Structure for mm-Wave 5G Applications. In Proceedings of the 2019 IEEE 4th International Conference on Computer and Communication Systems (ICCCS), Singapore, 23-25 February 2019. [CrossRef]

9. Lee, Y.; Sun, J. Compact Printed Slot Antennas for Wireless Dual- and Multi-Band Operations. Prog. Electromagn. Res. 2008, 88, 289-305. [CrossRef]

10. Lan, J.; Yu, Z.; Zhou, J.; Hong, W. An Aperture-Sharing Array for $(3.5,28) \mathrm{GHz}$ Terminals with Steerable Beam in Millimeter-Wave Band. IEEE Trans. Antennas Propag. 2020, 68, 4114-4119. [CrossRef]

11. Yang, X.; Ge, L.; Ji, Y.; Zeng, X.; Luk, K. Design of Low-Profile Multi-Band Half-Mode Substrate-Integrated Waveguide Antennas. IEEE Trans. Antennas Propag. 2019, 67, 6639-6644. [CrossRef]

12. di Paola, C.; Zhang, S.; Zhao, K.; Ying, Z.; Bolin, T.; Pedersen, G. Wideband Beam-Switchable $28 \mathrm{GHz}$ Quasi-Yagi Array for Mobile Devices. IEEE Trans. Antennas Propag. 2019, 67, 6870-6882. [CrossRef]

13. Go, H.; Jang, Y. Multi-band modified fork-shaped microstrip monopole antenna with ground plane including dual-triangle portion. Electron. Lett. 2004, 40, 575. [CrossRef]

14. al Abbas, E.; Ikram, M.; Mobashsher, A.; Abbosh, A. MIMO Antenna System for Multi-Band Millimeter-Wave 5G and Wideband 4G Mobile Communications. IEEE Access 2019, 7, 181916-181923. [CrossRef]

15. Wincza, K.; Gruszczynski, S. Broadband Scalable Antenna Arrays with Constant Beamwidths Fed by Frequency-Selective Networks. IEEE Trans. Antennas Propag. 2016, 64, 2936-2943. [CrossRef]

16. Wincza, K.; Gruszczynski, S. Frequency-Selective Feeding Network Based on Directional Filter for Constant-Beamwidth Scalable Antenna Arrays. IEEE Trans. Antennas Propag. 2017, 65, 4346-4350. [CrossRef]

17. Xie, Y.; Chen, F.; Qian, J. Design of Integrated Duplexing and Multi-Band Filtering Slot Antennas. IEEE Access 2020, 8, 126119-126126. [CrossRef]

18. Ávila-Navarro, E.; Carrasco, J.; Reig, C. Design of Yagi-like printed antennas for WLAN applications. Microw. Opt. Technol. Lett. 2007, 49, 2174-2178. [CrossRef]

19. Balanis, C.A. Antenna Theory Analysis and Design, 4th ed.; John Wiley \& Sons: New York, NY, USA, 2005.

Publisher's Note: MDPI stays neutral with regard to jurisdictional claims in published maps and institutional affiliations.

(C) 2020 by the authors. Licensee MDPI, Basel, Switzerland. This article is an open access article distributed under the terms and conditions of the Creative Commons Attribution (CC BY) license (http://creativecommons.org/licenses/by/4.0/). 